Review began 10/25/2021 Review ended 11/03/2021 Published 11/09/2021

๑) Copyright 2021

Santacruz et al. This is an open access article distributed under the terms of the Creative Commons Attribution License CCBY 4.0., which permits unrestricted use, distribution, and reproduction in any medium, provided the original author and source are credited.

\section{HIV and COVID-19 Coinfection: A Synergism That Results in More Severe Forms of Reactive Arthritis}

Juan Camilo Santacruz ${ }^{1}$, Marta Juliana Mantilla ${ }^{1}$, Sandra Pulido ${ }^{2}$, Angelo Arzuaga ${ }^{2}$, Juan Manuel Bello ${ }^{2}$, John Londono ${ }^{1}$

1. Spondyloarthropathies Research Group, Universidad de La Sabana, Chía, COL 2. Rheumatology, Universidad Militar Nueva Granada, Bogotá, COL

Corresponding author: Juan Camilo Santacruz, santa89@hotmail.com

Categories: HIV/AIDS, Infectious Disease, Rheumatology

Keywords: reactive arthritis, polyarticular compromise, covid 19, hiv, immune system

\title{
Introduction
}

The term "reactive arthritis" (ReA) was introduced in 1969 as an arthritis that appeared shortly after or during infection without achieving the identification of the microorganism in the joint tissue [1]. The original definition did not specify the pathogens that were accepted as causes of ReA and, in 1999, a panel of experts determined a specific list of gastrointestinal and urogenital pathogens that could be considered as possible causative agents [2]. Additionally, certain bacterial or viral respiratory infections (particularly COVID-19) have been associated with certain cases of ReA [3]. The human immunodeficiency virus (HIV) has also been associated as the causative agent of several joint syndromes, the most frequent being seronegative spondyloarthritis, rheumatoid arthritis, and joint pain syndrome [4]. However, some authors have considered that the cause of ReA in these cases is more related to exposure to other infections than to HIV per se [5]. Despite this, there is growing evidence today increasingly supporting the role of HIV as a possible cause of ReA. At present, it is unknown how COVID-19 infection can potentiate the immunosuppressive state caused by HIV, leading to more severe and atypical presentation of ReA along with the additional implication of limiting immunosuppressive treatment due to the inherent risk of potentially life-threatening infection.

\section{Case Presentation}

A 27-year-old male patient was admitted to a high-complexity institution due to a five-day clinical picture consisting of additive, symmetrical polyarticular pain, located in the wrists, knees, and left shoulder without other associated symptoms. The joint pain was continuous, permanent, and of great intensity that caused limitation of movement, mainly in the hands. In the systems review, no urinary or gastrointestinal symptoms were documented before the onset of joint symptoms. As the only relevant antecedent, he referred mild respiratory infection by severe acute respiratory syndrome coronavirus 2 (SARS-CoV-2) confirmed by reverse transcription-polymerase chain reaction the month before hospitalization. The initial clinical examination confirmed the presence of bilateral carpal synovitis, left suprapatellar synovitis, and synovitis of the sternoclavicular joints (Figures 1, 2, 3). 


\section{Cureus}

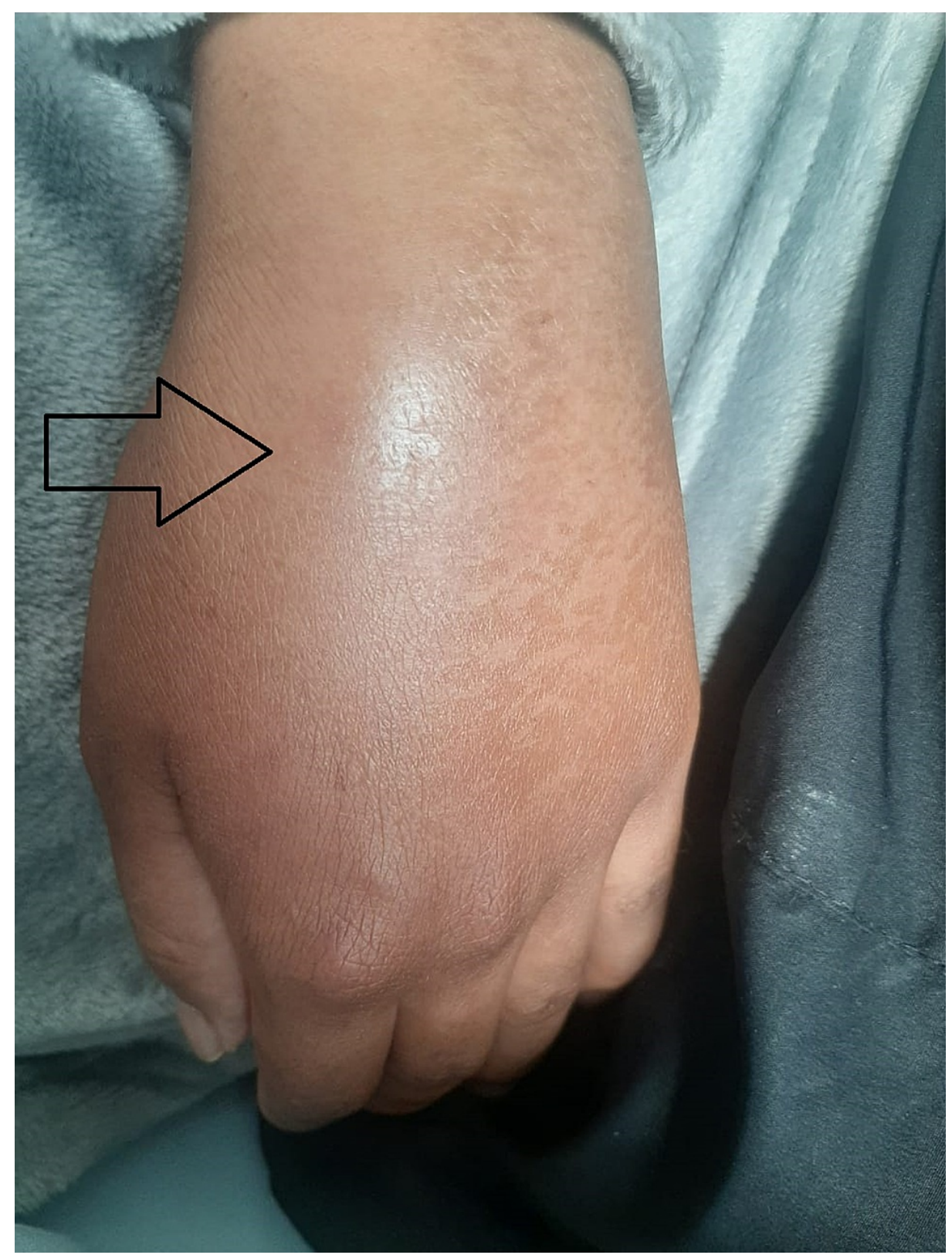

FIGURE 1: Left carpal synovitis 


\section{Cureus}

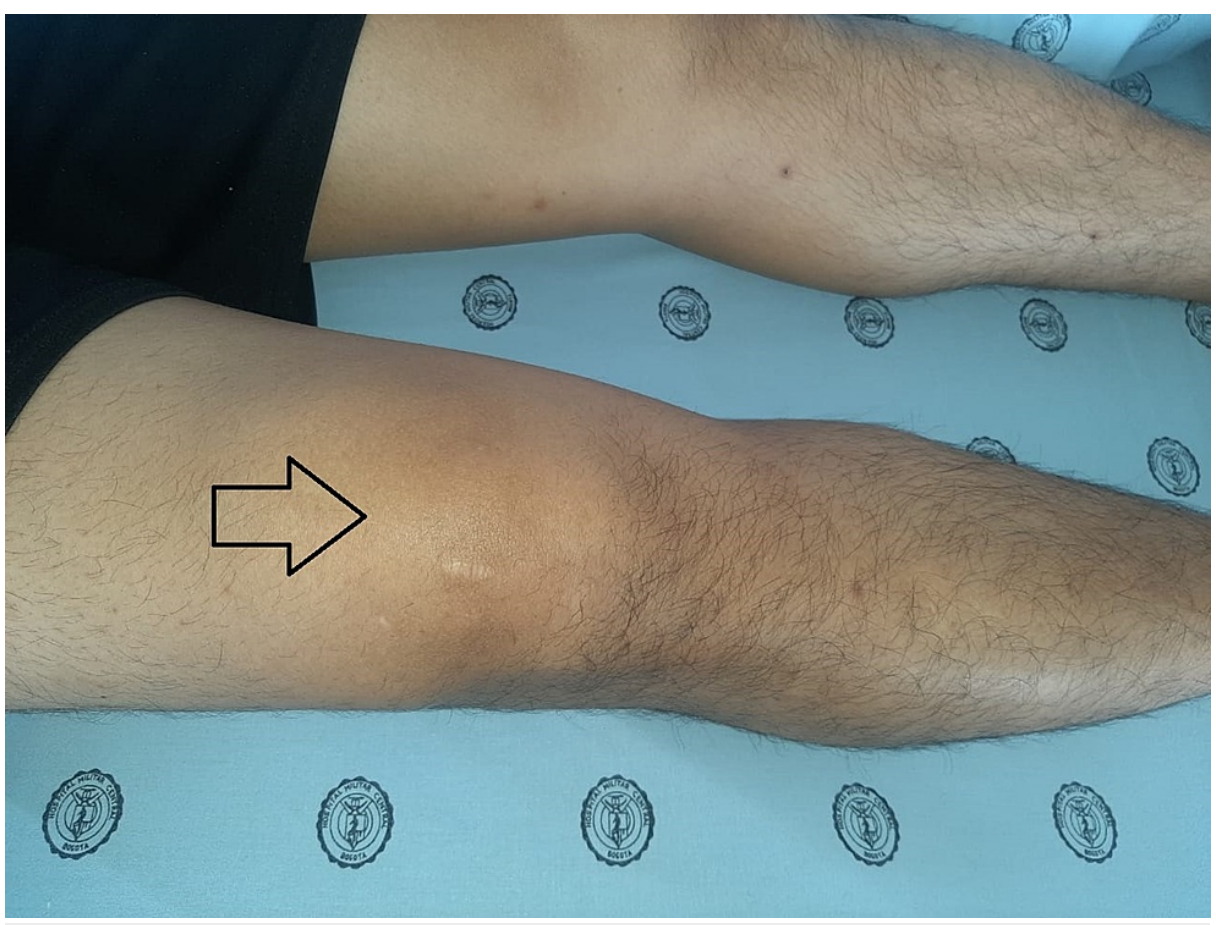

FIGURE 2: Left suprapatellar synovitis

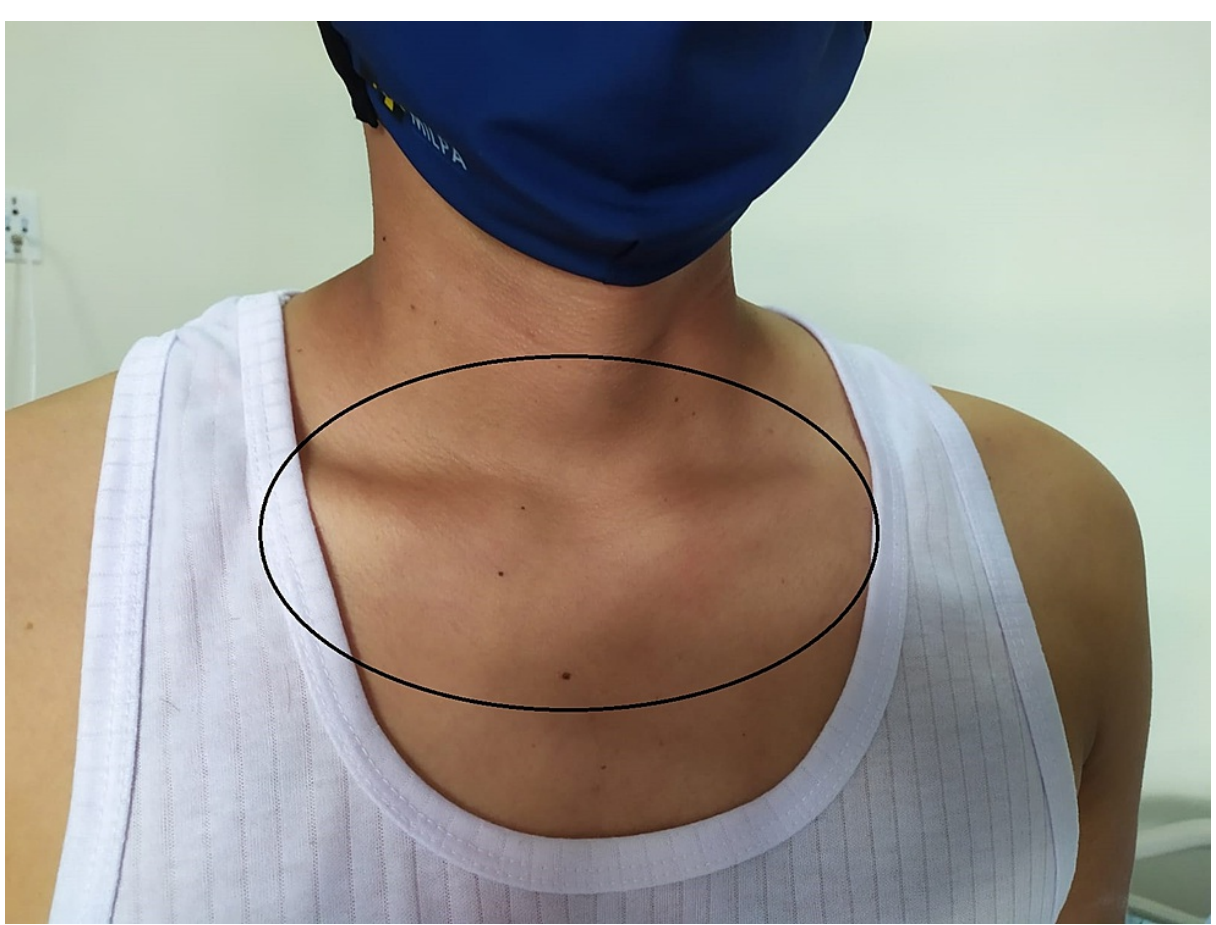

FIGURE 3: Sternoclavicular joint synovitis

Magnetic resonance imaging of the different compromised anatomical compartments was performed, presenting as additional findings the presence of bursitis of the lateral collateral ligament of the left lower limb and a peritendinous inflammatory process of the triangular fibrocartilage in the right wrist. Mild lymphopenia associated with a marked elevation of acute-phase reactants was documented in laboratory studies. Differential diagnoses of infectious etiology were sought, including a positive fourth-generation HIV enzyme-linked immunosorbent assay with a subsequent CD4 count of 98 cells $/ \mathrm{mm}^{3}$ and a viral load of 459,000 copies $/ \mathrm{mL}$. Treatment with prednisolone at a dose of $1 \mathrm{mg} / \mathrm{kg}$ and sulfasalazine ( $1 \mathrm{~g}$ per day) was initiated and no significant improvement in joint symptoms was noted despite sequential changes from disease-modifying antirheumatic drugs (DMARDs) such as methotrexate and leflunomide. Subsequently, the 


\section{Cureus}

patient achieved a complete joint response when antiretroviral therapy (abacavir,

dolutegravir/lamivudine) was initiated, thereby achieving a response to therapy resulting in gradual reduction of glucocorticoid doses and tapering to maintenance therapy solely with sulfasalazine. The description of the most representative laboratory studies upon admission and during hospitalization is shown in Table 1.

\begin{tabular}{|c|c|c|}
\hline Laboratory studies & Upon admission & Hospitalization \\
\hline Hemoglobin (g/dL) & 12.6 & 12.5 \\
\hline 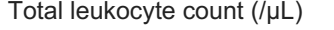 & 7920 & 8006 \\
\hline Total lymphocyte count $(/ \mu \mathrm{L})$ & 960 & 1200 \\
\hline Total platelet count $(/ \mu \mathrm{L})$ & 176,000 & 213,000 \\
\hline Creatinine (mg/dL) & 0.81 & 0.83 \\
\hline Ureic nitrogen (mg/dL) & 11.9 & 8.3 \\
\hline CRP (mg/dL) & 15.9 & 27 \\
\hline ESR (mm/h) & 68 & 88 \\
\hline Ferritin (ng/mL) & 829 & - \\
\hline HBSAg & Non-reactive & - \\
\hline Anti-HBc Ab & Non-reactive & - \\
\hline VDRL & Non-reactive & - \\
\hline HIV & Reactive & - \\
\hline $\mathrm{CD} 4+\left(\right.$ cells $\left./ \mathrm{mm}^{3}\right)$ & 98 & - \\
\hline HIV viral load (copies/mL) & 459,000 & - \\
\hline ANAS (titers) & Non-reactive & - \\
\hline ENAS (U/mL) & Non-reactive & - \\
\hline HLA - B27 & Negative & - \\
\hline Rheumatoid factor (U/mL) & Negative & - \\
\hline Anti-citrulline antibodies (U) & Negative & - \\
\hline Uroanalysis & Negative for infection & Negative for infection \\
\hline
\end{tabular}

\section{TABLE 1: Laboratory parameters at admission and during hospitalization}

ANAS: antinuclear antibodies; Anti-HBc Ab: hepatitis B core total antibodies; CRP: C-reactive protein; ENAS: extractable nuclear antigens; ESR: erythrocyte sedimentation rate; HBsAg: hepatitis B surface antigen; HIV: human immunodeficiency virus; HLA: human leukocyte antigen; VDRL: Venereal Disease Research Laboratory

\section{Discussion}

In the cases of ReA associated with HIV, the most characteristic presentation is an asymmetric oligoarthritis that more frequently involves the lower extremities associated with enthesitis. Extra-articular cutaneous manifestations such as blennorrhagic keratoderma and circinate balanitis are also common. Additionally, these patients can present extensive psoriasiform lesions that can even be confused with psoriatic arthritis [6]. Paradoxically, urethritis occurs with a similar frequency to patients with ReA without HIV. Axial involvement and uveitis are very rare forms of presentation. The distribution of HLA-B27 positivity is very heterogeneous, with a high frequency in Caucasians (80-90\%) with almost absolute negativity in African patients [7]. A lower frequency of involvement of the hand and wrist joints and multidigital dactylitis has also been described [8]. It is noteworthy that joint symptoms can manifest at any time during the course of the disease, but appear to be more frequent in the later stages of the infection [9]. The clinical course can vary from a mild joint involvement with a good response to the use of non-steroidal anti-inflammatory drugs, to a severe clinical picture, characterized by periostitis and multiple radiographic erosions [10]. Within the immunopathogenesis of ReA and its association with HIV, several theories have been 
proposed. The first one is that the acquired immunodeficiency syndrome (AIDS) would predispose the individual to bacterial, viral, and parasitic joint infections caused by arthritic microorganisms, which would favor the appearance of ReA. Another possibility would be that the immune dysfunction caused by AIDS would lead to an increase in the number of CD8+ T cells, with a reduction in CD4+ T cells, implicating a modification of immune regulation, with the possible induction of ReA [11]. In cases with HIV and COVID19 coinfection, additional alterations in the immune system have also been described, such as a decrease in regulatory $\mathrm{T}$ cells that contribute to the formation of dysfunctional $\mathrm{T}$ cells [12]. It has also been suggested that intestinal CD4+ T cells with mucosal protective $\mathrm{T}$ helper 17 functions are rapidly depleted leading to intestinal barrier dysfunction, favoring bacterial translocation and persistent immune activation [13]. It is noteworthy that both HIV-1 and SARS-CoV-2 infection share the loss of CD4+ T cells as a result of the disease-causing immunodeficiency. It has been suggested that both entities can cause direct attacks on CD4+ T cells, perpetuate immune activation, and redistribute CD4+ cells to lymph nodes and the intestine, reducing their concentration in peripheral blood. Additionally, lymphopenia is a hallmark of severe COVID19 patients and is associated with unfavorable clinical outcomes. Importantly, CD4+ T helper cells are vital in mediating humoral immunity by stimulating B cells to produce antibodies to these viruses. On the other hand, CD8+ T cells are responsible for the elimination of infected cells through the production of perforin and granzyme, being essential for viral control by the secretion of cytokines [14]. The loss of CD4+ T cells in both entities is demonstrated by the increase in biomarkers such as CD38, HLA-DR, and programmed death 1 (PD-1) that are expressed in activated T cells, contributing to their depletion [15]. Depleted virusspecific CD4+ T cells express PD-1 at high levels that correlate with disease progression, higher viral loads, and reduced T cell counts [16]. Regarding the treatment of ReA associated with HIV, it continues to be a controversial issue due to the possible exacerbation of viral infection due to the use of immunosuppressive drugs. However, if the patient does not respond to conventional symptomatic treatment, glucocorticoids and DMARDs should be considered, especially in refractory and persistent cases. Hydroxychloroquine is considered effective and safe among DMARDs, along with possible antiretroviral properties demonstrated in vitro. Sulfasalazine and cyclosporine are considered safe and effective, but experience with the latter is limited [17]. Methotrexate (at doses of $7.5 \mathrm{mg}$ to $15 \mathrm{mg}$ weekly) may also be a treatment option in HIVinfected patients, including those with AIDS, provided that antiretroviral therapy and chemoprophylaxis for Pneumocystis jirovecii infection are ensured [18]. The use of anti-tumor necrosis factor (TNF) has been proposed as a viable alternative for patients with HIV infection, without AIDS, who present with ReA refractory to other conventional DMARDs, also insisting on concomitant antiretroviral treatment. Data on the safety of immunomodulatory drugs in people living with HIV are limited. In a study using anti-TNF, antimetabolites, and checkpoint inhibitors, in which $95 \%$ of patients received joint antiretroviral therapy, there was a change in viral load (from undetectable to detectable) in the first year of treatment in $41.2 \%$. Additionally, $11.8 \%$ of the patients presented an additional severe infection not directly associated with the drug, even with a median CD4+ T cell count of 609 cells/ $\mu \mathrm{L}$. Given these findings, careful monitoring is required to detect signs of virologic relapse and incident infections [19]. Highly effective antiretroviral therapies (HAARTs) have managed to increase the lymphocyte count, improve survival, have changes in the profile of immune responses, and direct cellular metabolic changes, which is why their early initiation is of vital importance [20].

\section{Conclusions}

ReA among patients with HIV and COVID-19 causes important alterations in the innate and adaptive immune system, particularly due to the dysregulation and depletion of $\mathrm{T}$ cells, favoring higher levels of immunosuppression. This favors the increase of pro-inflammatory cytokines that can cause a change in the clinical expression of the disease, leading to more serious forms of presentation such as polyarticular involvement. This may also be reflected in the persistent elevation of acute-phase reactants and poor response to DMARDs and glucocorticoids. No studies have been conducted to evaluate the clinical response rates to the use of anti-TNF in patients with AIDS and CD4+ less than 200 cells $/ \mathrm{mm}^{3}$; however, there is a substantial risk of virological relapse and incident infections even with CD4+ cell counts greater than 200 cells $/ \mathrm{mm}^{3}$. Concerning the joint response, the risk and benefit of this treatment must be evaluated. HAART therapy is essential to attenuate these alterations in the immune system, achieve early clinical improvement, and be able to have better responses to conventional and biological DMARDs.

\section{Additional Information \\ Disclosures}

Human subjects: Consent was obtained or waived by all participants in this study. Conflicts of interest: In compliance with the ICMJE uniform disclosure form, all authors declare the following: Payment/services info: All authors have declared that no financial support was received from any organization for the submitted work. Financial relationships: All authors have declared that they have no financial relationships at present or within the previous three years with any organizations that might have an interest in the submitted work. Other relationships: All authors have declared that there are no other relationships or activities that could appear to have influenced the submitted work.

\section{References}

1. Ahvonen P, Sievers K, Aho K: Arthritis associated with Yersinia enterocolitica infection. Acta Rheumatol 
Scand. 1969, 15:232-53. 10.3109/rhe1.1969.15.issue-1-4.32

2. Braun J, Kingsley G, van der Heijde D, Sieper J: On the difficulties of establishing a consensus on the definition of and diagnostic investigations for reactive arthritis. Results and discussion of a questionnaire prepared for the 4th International Workshop on Reactive Arthritis, Berlin, Germany, July 3-6, 1999. J Rheumatol. 2000, 27:2185-92.

3. Keynan Y, Rimar D: Reactive arthritis--the appropriate name. Isr Med Assoc J. 2008, 10:256-8.

4. Adizie T, Moots RJ, Hodkinson B, French N, Adebajo AO: Inflammatory arthritis in HIV positive patients: a practical guide. BMC Infect Dis. 2016, 16:100. 10.1186/s12879-016-1389-2

5. Clark MR, Solinger AM, Hochberg MC: Human immunodeficiency virus infection is not associated with Reiter's syndrome. Data from three large cohort studies. Rheum Dis Clin North Am. 1992, 18:267-76.

6. Mody G, Parke FA, Reveille JD: Articular manifestations of human immunodeficiency virus infection. Best Pract Res Clin Rheumatol. 2003, 17:265-87. 10.1016/S1521-6942(03)00003-2

7. Espinoza LR, García-Valladares I: Of bugs and joints: the relationship between infection and joints . Reumatol Clin. 2013, 9:229-38. 10.1016/j.reuma.2012.06.008

8. Berman A, Espinoza LR, Diaz JD, et al.: Rheumatic manifestations of human immunodeficiency virus infection. Am J Med. 1988, 85:59-64. 10.1016/0002-9343(88)90503-7

9. Cuellar ML, Espinoza LR: Rheumatic manifestations of HIV-AIDS. Baillieres Best Pract Res Clin Rheumatol. 2000, 14:579-93. 10.1053/berh.2000.0094

10. Winchester R, Brancato L, Itescu S, Skovron ML, Solomon G: Implications from the occurrence of reiter's syndrome and related disorders in association with advanced HIV infection. Scand J Rheumatol. 1988, 74:89-93. 10.3109/03009748809102943

11. Malta JB, Milanelo D, Carvalheiro FA, Silva MV: Reiter's syndrome associated with the acquired immunodeficiency syndrome: a case report. Braz J Infect Dis. 2002, 6:40-4. 10.1590/s141386702002000100006

12. Moreno-Fernandez ME, Presicce P, Chougnet CA: Homeostasis and function of regulatory T cells in HIV/SIV infection. J Virol. 2012, 86:10262-9. 10.1128/JVI.00993-12

13. Bixler SL, Mattapallil JJ: Loss and dysregulation of Th17 cells during HIV infection. Clin Dev Immunol. 2013, 2013:852418. 10.1155/2013/852418

14. Peng X, Ouyang J, Isnard S, Lin J, Fombuena B, Zhu B, Routy JP: Sharing CD4+ T cell loss: when COVID-19 and HIV collide on immune system. Front Immunol. 2020, 11:596631. 10.3389/fimmu.2020.596631

15. Papagno L, Spina CA, Marchant A, et al.: Immune activation and CD8+ T-cell differentiation towards senescence in HIV-1 infection. PLoS Biol. 2004, 2:E20. 10.1371/journal.pbio.0020020

16. Trautmann L, Janbazian L, Chomont N, et al.: Upregulation of PD-1 expression on HIV-specific CD8+ T cells leads to reversible immune dysfunction. Nat Med. 2006, 12:1198-202. 10.1038/nm1482

17. Henrique da Mota LM, Carneiro JN, Lima RA, dos Santos Neto LL, Lima FA: [Reactive arthritis in HIVinfected patients: immunopathogenic aspects]. Acta Reumatol Port. 2008, 33:279-87.

18. Naides SJ: Viral arthritis including HIV. Curr Opin Rheumatol. 1995, 7:337-42.

19. Peluso MJ, Chen J, Munter S, et al.: Outcomes of immunomodulatory and biologic therapy in people living with HIV. AIDS. 2020, 34:1171-9. 10.1097/QAD.0000000000002549

20. Calabrese LH, Kirchner E, Shrestha R: Rheumatic complications of human immunodeficiency virus infection in the era of highly active antiretroviral therapy: emergence of a new syndrome of immune reconstitution and changing patterns of disease. Semin Arthritis Rheum. 2005, 35:166-74.

10.1016/j.semarthrit.2005.03.007 